\title{
Preparation of lead oxide nanoparticles from cathode-ray tube funnel glass by self-propagating method
}

\author{
Yu Wang ${ }^{\mathrm{a}, \mathrm{b}}$, Jianxin Zhu ${ }^{\mathrm{a}, *}$ \\ a Research Center for Eco-Environmental Sciences, Chinese Academy of Sciences, Beijing 100085, China \\ ${ }^{\mathrm{b}}$ Graduate University of the Chinese Academy of Sciences, Beijing 100049, China
}

\section{A R T I C L E I N F O}

\section{Article history:}

Received 9 October 2011

Received in revised form 8 December 2011

Accepted 14 February 2012

Available online 22 February 2012

\section{Keywords:}

Self-propagating high-temperature

synthesis

Cathode-ray tube

Funnel glass

Extraction

Lead oxide

TCLP

\begin{abstract}
A B S T R A C T
This paper presents a novel process of extracting lead oxide nanoparticles from cathode-ray tube (CRT) funnel glass using self-propagating high-temperature synthesis (SHS) method. The impacts of added amount of funnel glass on the extraction ratio of lead, the lead extraction velocity and the micromorphology, as well as particle size of extracted nanoparticles were investigated. We found that self-propagating reaction in the presence of $\mathrm{Mg}$ and $\mathrm{Fe}_{2} \mathrm{O}_{3}$ could separate lead preferentially and superfine lead oxide nanoparticles were obtained from a collecting chamber. The separation ratio was related closely to the amount of funnel glass added in the original mixture. At funnel glass addition of no more than $40 \mathrm{wt} . \%$, over $90 \mathrm{wt} . \%$ of lead was recovered from funnel glass. High extraction yield reveals that the network structure of funnel glass was fractured due to the dramatic energy generated during the SHS melting process. The $\mathrm{PbO}$ nanoparticles collected show good dispersion and morphology with a mean grain size of $40-50 \mathrm{~nm}$.
\end{abstract}

(c) 2012 Elsevier B.V. All rights reserved.

\section{Introduction}

Waste cathode-ray tubes (CRT) from televisions or computer monitors are growing at an escalating rate because of the widespread use of LCD screens and replacement of electronic products in these years [1-3]. A recent study has estimated that the amount of CRT glass generated in Asia will increase with a factor of two and climb up from 800 to 1500 metric tons by 2020 [4]. As one of the biggest manufacturers and consumers of electronic appliances, China will face its sharp rise of obsolete personal computers and televisions between 2008 and 2012 [5]. The estimated amount of discarded PCs and TVs will reach 93.36 and 74.31 million units in 2012, respectively [6,7]. In addition, the "trade-in policy of home appliances" and illegal importation also enlarge the size of waste CRT stream in China. The proper recycling or disposing of waste CRTs is a very important issue in response to its growing volume.

The treatment of funnel glass is one of the major challenges in the recycling of waste CRT glass due to its high lead concentration. The funnel glass is designed and produced with $20-30 \mathrm{wt} . \%$ of lead to stabilize the glass and absorb X-ray radiation emitted by the electron gun in televisions or computer monitors [8]. However, the

\footnotetext{
* Corresponding author. Tel.: +86 10 62849488; fax: +861062849515

E-mail address: Zhujx@rcees.ac.cn (J. Zhu).
}

lead existed in the waste CRTs possess a high risk to the human health, which has irreversible effects on the central and peripheral nervous systems, blood system, kidneys, as well as the endocrine system [9]. Currently, the vast majority of non-recycled CRTs end up in landfills or incinerators, which may make secondary pollution to the environment. It is well known that even the "state of the art" landfill is not completely sealed and a certain amount of chemical and heavy metal leakage may occur. The heavy metal lead may also emit into the environment with the flue gas and incineration fly ash. More and more countries prohibit the landfill and incineration of waste CRTs [10,11].

However, it is hard to separate lead from waste CRTs, because lead exits in the funnel glass as a network intermediate. $\mathrm{PbO}_{3}$ polyhedron is the dominant structural unit in the funnel glass with an average $\mathrm{Pb}-\mathrm{O}$ distance of $22.4 \mathrm{~nm}$. The $\mathrm{PbO}_{3}$ polyhedrons are encapsulated firmly between $\mathrm{SiO}_{4}$ tetrahedrons and high energy is needed to break the three-dimensional vitreous network [12-15]. A number of methods such as pyrometallurgy, subcritical hydrothermal, power ultrasound and mechanochemical processes have previously been developed and employed for the treatment of waste CRTs [16-21]. Among them, pyrometallurgy technology was proven an effective way of lead separation from funnel glass. Yot et al. [18] extracted $40 \mathrm{wt} . \%$ of total lead from waste CRTs by reaction with siliconcarbide after $60 \mathrm{~min}$ at $1223 \mathrm{~K}$ under the atmospheric pressure. Xing and Zhang [16] and Chen et al. [17] recovered more than $90 \mathrm{wt} . \%$ of total from funnel glass at $1273 \mathrm{~K}$ 
Table 1

Chemical compositions (wt.\%) of investigated CRT funnel glass by XRF.

\begin{tabular}{lr}
\hline Components & \multicolumn{1}{l}{ wt.\% } \\
\hline $\mathrm{SiO}_{2}$ & $52.45 \pm 2.01$ \\
$\mathrm{PbO}$ & $22.89 \pm 0.91$ \\
$\mathrm{~K}_{2} \mathrm{O}$ & $8.66 \pm 0.62$ \\
$\mathrm{Na}_{2} \mathrm{O}$ & $5.67 \pm 0.25$ \\
$\mathrm{Al}_{2} \mathrm{O}_{3}$ & $3.68 \pm 0.04$ \\
$\mathrm{CaO}$ & $2.74 \pm 0.31$ \\
$\mathrm{MgO}$ & $2.43 \pm 0.66$ \\
\hline
\end{tabular}

via reaction with carbon powder under vacuum condition. These articles showed that the process is time-consuming (1-4h) and needs a high temperature $(>1200 \mathrm{~K})$ to break the network structure of lead silicate and separate lead from funnel glass by the traditional pyrometallurgy method. The development of a novel high-temperature process with less energy and time consumption is necessary and meaningful to recycle CRT in an environmentally friendly way.

The self-propagating high-temperature synthesis (SHS) method is well known as an attractive alternative to the conventional methods for manufacturing advanced materials, such as ceramics, ceramic-composites and intermetallic compounds, since SHS provides advantages with respect to process economics, short reaction time and energy efficiency [22,23]. Previous researchers have explored the usage of SHS in the disposing various solid wastes [24-26]. The underlying characteristic of SHS relies on the highly exothermic reaction could be ignited in the form of self-sustaining combustion wave quickly from one side to another without additional energy, thus energetically efficient and procedurally short. Moreover, the high combustion temperature achieved during the SHS process is always above $1800 \mathrm{~K}$, at which funnel glass could be easily melted and PbO in the waste CRTs could be effectively volatilized and separated. In addition, rapid cooling rate of evaporated phase might give rise to the formation of $\mathrm{PbO}$ nanoparticles.

This work aimed to investigate the possibility of preparing lead oxide nanoparticles from CRT funnel glass by the self-propagating process. The effects of elaborate parameters on the SHS combustion, lead extraction and crystallization process are described. The toxicity of the residues after SHS treatment was also studied by Toxicity Characteristic Leaching Procedure (TCLP).

\section{Materials and methods}

\subsection{Materials}

Funnel glass of wasted CRTs from Huaxing Environmental Protection Corporation (Beijing, China) was pulverized by the planetary ball-milling (through 80 sieve mesh) and dried at $378 \mathrm{~K}$ for $24 \mathrm{~h}$ prior to use, whose chemical composition was presented in Table 1. Commercial ferric oxide (purity 99\%, particle size $<5 \mu \mathrm{m}$ ) and magnesium (purity 99\%, particle size 200 mesh) were used as the SHS reactants, and their contents were computed according to the stoichiometry of the following reaction:

$3 \mathrm{Mg}+\mathrm{Fe}_{2} \mathrm{O}_{3}=3 \mathrm{MgO}+2 \mathrm{Fe}, \quad \Delta H_{298}=980.6 \mathrm{~kJ} / \mathrm{mol}$

The combustion enthalpy of reaction (1) was calculated from the formation enthalpies of $\mathrm{Fe}_{2} \mathrm{O}_{3}$ and $\mathrm{MgO}$ at $298 \mathrm{~K}$. All the data needed were referred from the Lange's Handbook of Chemistry [27]. It could be found that the value of $\Delta H_{298} / \mathrm{C}_{\mathrm{p} 298}$ is about $6061 \mathrm{~K}$. Thus, this thermite reaction satisfies the experience criteria $\left(\Delta \mathrm{H}_{298} / \mathrm{C}_{\mathrm{p} 298} \geq 2000 \mathrm{~K}\right)$ of high-temperature self-propagation reaction proposed by Merzhanov.
Table 2

Summary of the mixtures (wt.\%) investigated.

\begin{tabular}{llll}
\hline Sample No. & Funnel glass (wt.\%) & $\mathrm{Fe}_{2} \mathrm{O}_{3}(w \mathrm{wt} . \%)$ & $\mathrm{Mg}(\mathrm{wt} . \%)$ \\
\hline CRT10 & 10.00 & 61.79 & 28.21 \\
CRT20 & 20.00 & 54.92 & 25.08 \\
CRT30 & 30.00 & 48.06 & 21.94 \\
CRT40 & 40.00 & 41.19 & 18.81 \\
CRT50 & 50.00 & 34.33 & 15.67 \\
CRT60 & 60.00 & 27.46 & 12.54 \\
\hline
\end{tabular}

\subsection{Self-propagating extraction process}

CRT funnel glass, magnesium and ferric oxide powders were mixed as the contents shown in Table 2. Parallelepiped shaped samples with dimensions $40 \mathrm{~mm} \times 8 \mathrm{~mm} \times 7 \mathrm{~mm}$ and green densities in the range from 2.19 to $2.32 \mathrm{~g} / \mathrm{cm}^{3}$ were prepared by uniaxial pressing into a steel die with a pressure of $10 \mathrm{MPa}$ for approximately two minutes. Each sample was located vertically in a small SHS reaction chamber with dimensions $100 \mathrm{~mm} \times 100 \mathrm{~mm} \times 100 \mathrm{~mm}$, an electrically heated graphite rod at the top of the pellet initiated the reaction. A stopwatch was used to measure the combustion velocity and an infrared pyrometer (Raytek 3i series, Raytek, U.S.) was employed to measure the maximum combustion temperature. As observed in the experimental process, each sample self-propagated through the medium immediately after ignition in the form of a bright combustion front as a consequence of high energy generated from the exothermic reaction between $\mathrm{Fe}_{2} \mathrm{O}_{3}$ and $\mathrm{Mg}$. Two solid products, residue and extract, were obtained. The extract was condensed on the reaction chamber walls due to the evaporation occurring during the SHS process while the residue remained where the original compact was placed inside the vessel.

\subsection{Analysis}

Crystalline compounds of the final solid products, both residues and extracts, were characterized by X-ray diffractometer (XRD, X'Pert PRO MPD, PANalytical, Netherlands) using the Ni-filtered $\mathrm{CuK} \alpha$ radiation over an angle of $10^{\circ}<2 \theta<90^{\circ}$. The XRD data were identified by MDI Jade 5.0 software with ICDD PDF2003 database. The microstructures were observed by scanning electron microscope combined with energy dispersive X-ray spectroscopy (SEM-EDX, S-3000N, Hitachi, Japan) and transmission electron microscopy (TEM, H-7500, Hitachi, Japan). Quantitative analysis of metal contents was carried out by inductively coupled plasma optical emission spectrometer (ICP-OES, OPTIMA 2000, PerkinElmer, U.S.) analysis of the solution obtained after the solid products were fully dissolved into an aqueous mixture of $\mathrm{HNO}_{3}, \mathrm{HCL}$ and $\mathrm{HF}$. Leaching behavior of the obtained residues was determined according to the Toxicity Characteristic Leaching Procedure (TCLP, Method 1311, USEPA) [28].

\section{Results and discussion}

\subsection{Separation of lead by SHS process}

Fig. 1 shows the dependence of extraction ratio of lead and combustion temperature $\left(T_{\mathrm{c}}\right)$ on the amount of funnel glass added in the original mixture. It could be found that the self-propagating reaction in the presence of $\mathrm{Mg}$ and $\mathrm{Fe}_{2} \mathrm{O}_{3}$ can extract lead from funnel glass, and the extraction ratio changes with the content of funnel glass. Specifically, the extraction ratio of lead reaches over $90 \mathrm{wt} . \%$ when the funnel glass addition is no more than $40 \mathrm{wt} . \%$. The lead extraction exhibits a significant negative correlation with the funnel glass addition, while it shows a positive relationship with the combustion temperature. This result indicates that the extraction 


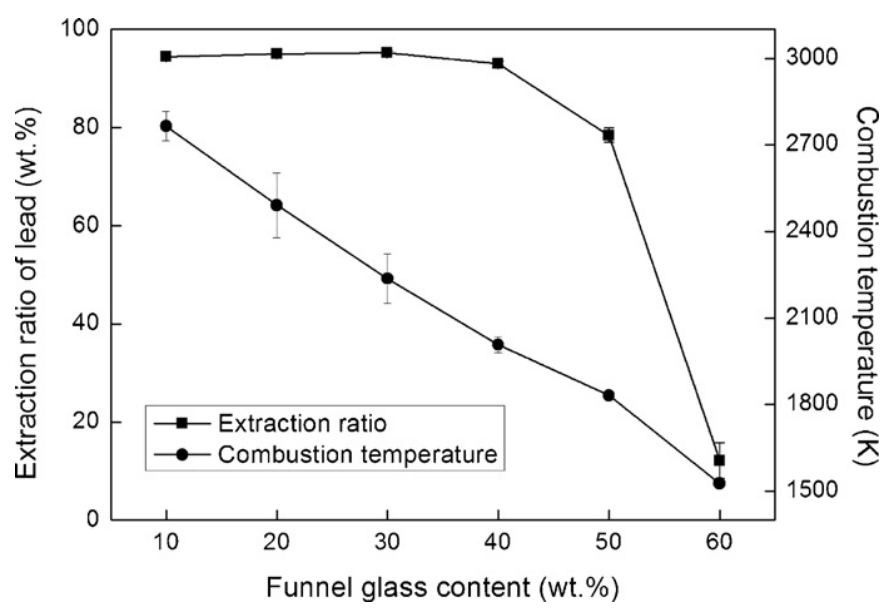

Fig. 1. Effect of funnel glass addition in the original mixture on the lead extraction ratio and combustion temperature.

Table 3

Melting and boiling points of major compositions contained in funnel glass.

\begin{tabular}{llc}
\hline Composition & Melting point $(\mathrm{K})$ & Boiling point $^{\mathrm{a}}(\mathrm{K})$ \\
\hline $\mathrm{PbO}$ & 1159 & 1745 \\
$\mathrm{~K}_{2} \mathrm{O}$ & 623 Decomposition & - \\
$\mathrm{Na}_{2} \mathrm{O}$ & Sublimation & - \\
$\mathrm{Al}_{2} \mathrm{O}_{3}$ & 2327 & 3253 \\
$\mathrm{Fe}_{2} \mathrm{O}_{3}$ & 1838 Decomposition & - \\
$\mathrm{MgO}$ & 3073 & 3873 \\
$\mathrm{CaO}$ & 3173 & 3773 \\
\hline
\end{tabular}

a Boiling point is given at atmosphere pressure $(760 \mathrm{~mm}$ of mercury or $101,325 \mathrm{~Pa})$.

of lead from funnel glass might arise from lead evaporation at the extreme high temperature achieved during the SHS reaction. So the extraction ratio drastically decreased with a lower combustion temperature when the funnel glass addition is more than $40 \mathrm{wt} . \%$. On one hand, the exothermicity and combustion temperature of SHS reactions decrease with increasing funnel glass content. Lead is difficult to be evaporated when the combustion temperature is lower than $1900 \mathrm{~K}$ and close to the boiling point of lead oxide (cf. Table 3), which is the main phase of lead in funnel glass. For example, the extraction ratio of lead was only 12.14 wt.\% with $60 \mathrm{wt} . \%$ funnel glass addition. On the other hand, relatively slow combustion velocity and rapid cooling rate at conditions of higher funnel glass addition gave rise to the gasified lead encapsulated in the residue again before escaping from the funnel glass during the SHS process. Thus, it is worth noting that the addition of funnel glass as a diluent can be used to control the SHS lead extraction behavior.

The lead extraction in the SHS process is analogous to the vacuum metallurgy separation method, which utilizes the difference of boiling points of various metals to separate the mixture of metals [29]. That is to say, the composition with high vapor pressure and low boiling point can be separated through evaporation or sublimation from other components which were still remained in

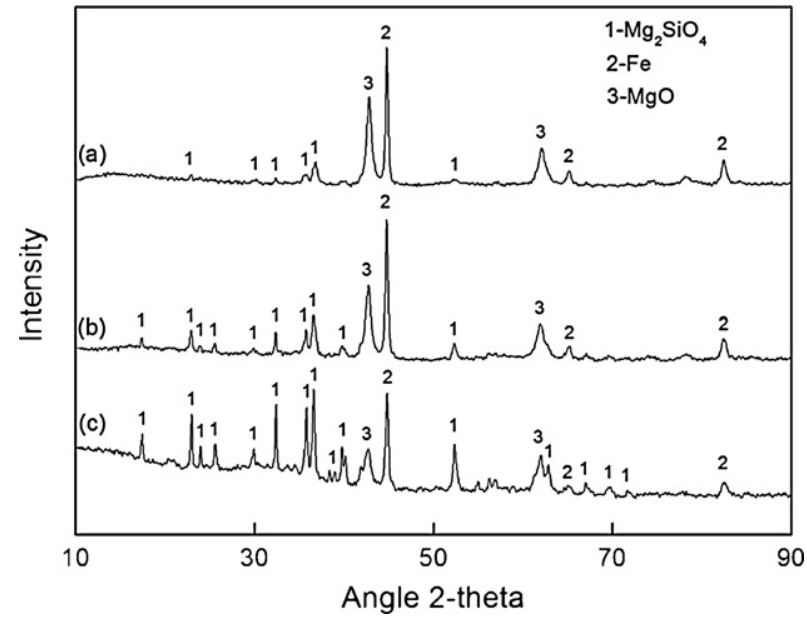

Fig. 2. XRD patterns of the residues in the cases of funnel glass addition ranging: (a) $10 \mathrm{wt} . \%$, (b) $30 \mathrm{wt} . \%$, (c) $50 \mathrm{wt} . \%$.

the residue during the SHS process. Table 3 lists the boiling points of major components involved in funnel glass [27,30]. It could be found that $\mathrm{PbO}$ with relatively low boiling point is inclined to evaporate when compared with $\mathrm{Al}_{2} \mathrm{O}_{3}, \mathrm{MgO}$ and $\mathrm{CaO}$. Obviously, this SHS regime could easily extract $\mathrm{PbO}$ but prevent $\mathrm{Al}_{2} \mathrm{O}_{3}, \mathrm{MgO}$ and $\mathrm{CaO}$ from evaporating. In addition, $\mathrm{K}_{2} \mathrm{O}$ could be decomposed when the temperature reaches $623 \mathrm{~K}$ and $\mathrm{Na}_{2} \mathrm{O}$ is easy to sublimate at high temperature. As observed in the ICP-OES tests, a few quantities of potassium and sodium were also evaporated with $\mathrm{PbO}$ at the same time. However, because of the relatively low concentrations of potassium and sodium contained in funnel glass, the evaporated content contributes to a relatively small fraction of the mass of total extract (cf. Table 4). The extracted potassium and sodium were only $4.69 \mathrm{~g} / \mathrm{kg}$ and $1.49 \mathrm{~g} / \mathrm{kg}$, respectively, while the lead extract was about $84.46 \mathrm{~g} / \mathrm{kg}$ with $50 \mathrm{wt}$.\% of funnel glass addition, as presented in Table 4.

The XRD patterns of the residues obtained after self-propagating with $10 \mathrm{wt} . \%, 30 \mathrm{wt} . \%$ and $50 \mathrm{wt} . \%$ funnel glass addition were shown in Fig. 2. No significant differences were observed among them and the main crystalline phases contained $\mathrm{Mg}_{2} \mathrm{SiO}_{4}$ (PDF card \#340189), MgO (PDF card \#45-0946) and Fe (PDF card \#65-4899). Thus, it can be inferred that part of the $\mathrm{MgO}$ produced in the reaction (1) combined together with $\mathrm{SiO}_{2}$ to form $\mathrm{Mg}_{2} \mathrm{SiO}_{4}$. Moreover, it is worth noting that $\mathrm{Mg}_{2} \mathrm{SiO}_{4}$ and $\mathrm{MgO}$ were not easy to evaporate due to their high boiling points. In addition, iron reduced in the reaction (1) was also difficult to volatilize because it was prone to enrich and contact with each other during the SHS melting process. It can be observed in the back-scattered SEM micrograph of residue with EDX elemental analysis (cf. Fig. 3). The spherical iron particles are in the micron order without significant impurities, distributing randomly on the surface of the residue. The bulks of iron particles were formed from the enrichment of metallic iron during the self-propagating process, which prevented Fe from separation.

Table 4

Extraction amount of major metals (g per kg original mixture) with different funnel glass addition (wt.\%) in the original mixture.

\begin{tabular}{|c|c|c|c|c|c|c|c|}
\hline \multirow[t]{2}{*}{ Funnel glass content (wt.\%) } & \multicolumn{7}{|c|}{ Extraction amount $(\mathrm{g} / \mathrm{kg})$} \\
\hline & $\mathrm{Pb}$ & K & $\mathrm{Na}$ & $\mathrm{Fe}$ & $\mathrm{Mg}$ & $\mathrm{Al}$ & $\mathrm{Ca}$ \\
\hline 10.00 & $20.02 \pm 0.14$ & $6.20 \pm 0.02$ & $3.51 \pm 0.001$ & $3.68 \pm 0.50$ & $3.70 \pm 0.31$ & $0.03 \pm 0.002$ & $0.10 \pm 0.002$ \\
\hline 20.00 & $40.23 \pm 0.30$ & $12.22 \pm 0.09$ & $6.42 \pm 0.002$ & $3.98 \pm 0.40$ & $2.52 \pm 0.24$ & $0.02 \pm 0.004$ & $0.15 \pm 0.004$ \\
\hline 30.00 & $60.74 \pm 0.18$ & $13.09 \pm 0.40$ & $5.34 \pm 0.001$ & $0.83 \pm 0.04$ & $2.38 \pm 0.03$ & $0.02 \pm 0.001$ & $0.07 \pm 0.001$ \\
\hline 40.00 & $79.21 \pm 0.59$ & $7.24 \pm 0.79$ & $2.56 \pm 0.09$ & $0.91 \pm 0.19$ & $2.21 \pm 0.12$ & $0.09 \pm 0.005$ & $0.07 \pm 0.005$ \\
\hline 50.00 & $84.46 \pm 2.50$ & $4.69 \pm 0.11$ & $1.49 \pm 0.01$ & $0.69 \pm 0.01$ & $1.28 \pm 0.05$ & $0.02 \pm 0.001$ & $0.07 \pm 0.002$ \\
\hline 60.00 & $15.49 \pm 2.72$ & $3.92 \pm 0.86$ & $0.67 \pm 0.07$ & $0.00 \pm 0.00$ & $0.03 \pm 0.001$ & $0.00 \pm 0.00$ & $0.01 \pm 0.001$ \\
\hline
\end{tabular}




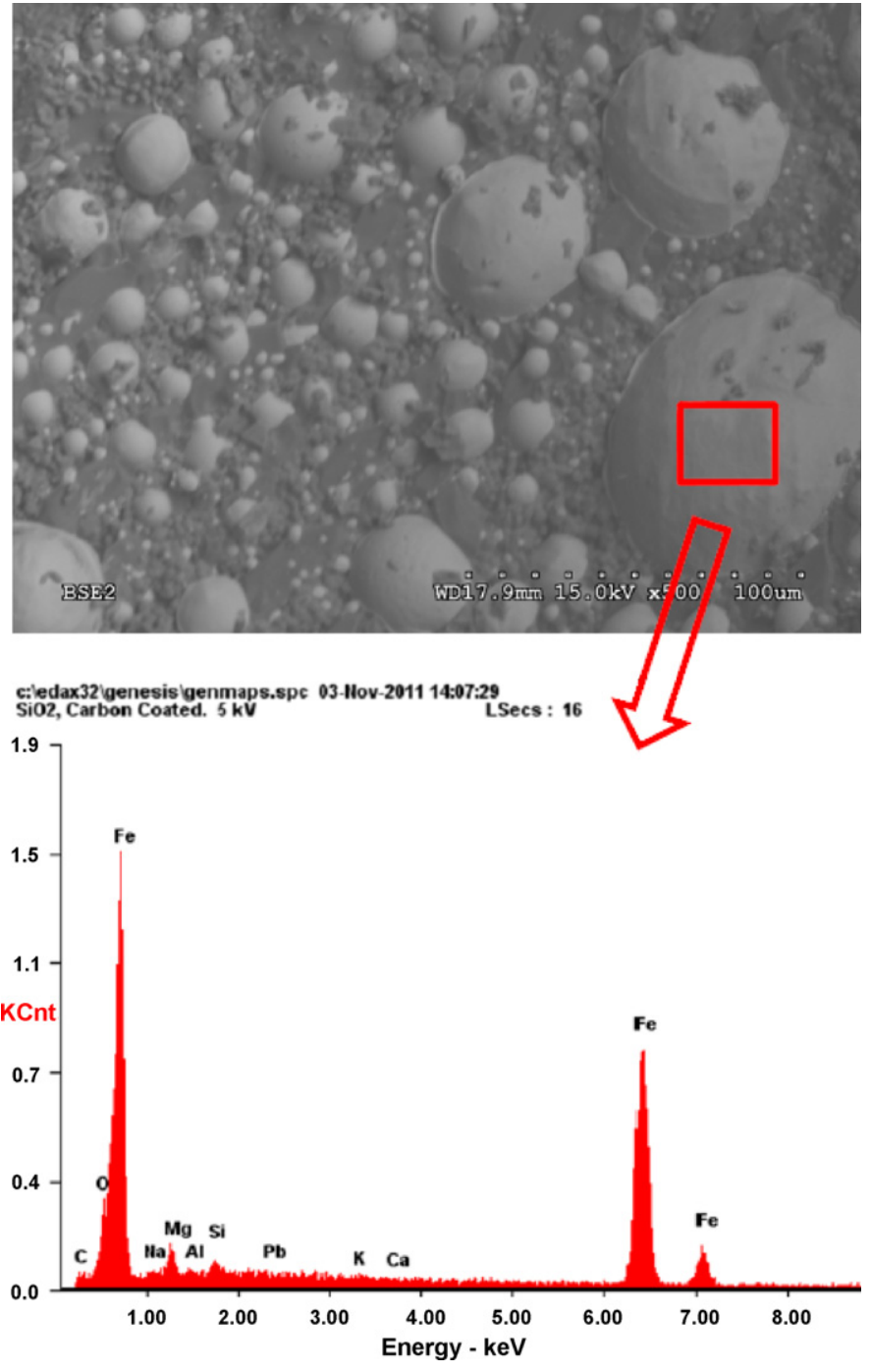

Fig. 3. A typical SEM back-scattered micrograph with EDX elemental analysis of the surface of the residue under the condition of funnel glass added $30 \mathrm{wt} . \%$ in the original mixture.

\subsection{Lead extraction kinetics}

The lead evaporation velocity in the SHS process could be calculated by Eq. (2):

$\omega=\frac{\Delta W}{t \times A}$

where $\omega\left(\mathrm{g} / \mathrm{cm}^{2} \mathrm{~s}\right)$ is the evaporation velocity of lead, $\Delta W(\mathrm{~g})$ is the evaporated amount of lead, $A\left(\mathrm{~cm}^{2}\right)$ is evaporation surface area and $t(\mathrm{~s})$ is the evaporation time which is obtained from the plot of temperature evolution as a function of time.

A typical temperature-time profile during SHS reaction for a sample with 40 wt.\% funnel glass addition was shown in Fig. 4. After the sample was ignited, the combustion wave self-propagated toward the spot targeted by the laser of the infrared pyrometer. As the combustion wave reached the location of laser, the temperature increased sharply to the maximum temperature in a short time, after that, the residue cooled down quickly by heat dissipation to the environment. As mentioned in the references [16], the requirement of temperature to separate lead from funnel glass by pyrometallurgy should be higher than $1273 \mathrm{~K}$. Thus, we assume that the temperature above $1273 \mathrm{~K}$ is efficient for extraction of lead during SHS process, and the evaporation time of lead at each spot is the

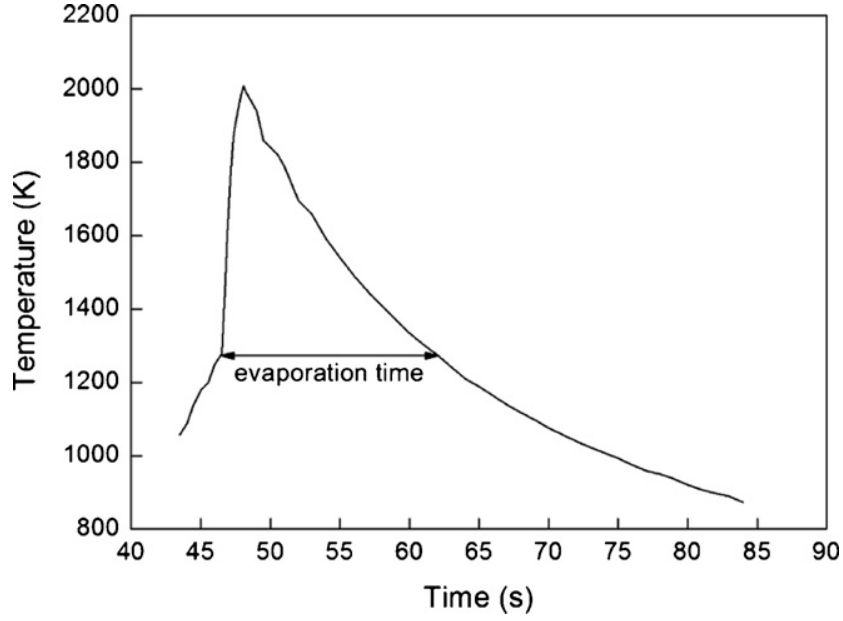

Fig. 4. A typical temperature-time profile during SHS reaction for a sample with $40 \mathrm{wt} . \%$ added funnel glass content.

time it used to maintain its temperature at more than $1273 \mathrm{~K}$ (cf. Fig. 4).

Fig. 5 shows the dependence of the evaporation velocity of lead on the funnel glass addition. It could be found that evaporation velocity firstly increased with increasing the funnel glass addition, to a maximum value in the case of funnel glass added equal to $40 \mathrm{wt} . \%$, and then decreased when funnel glass addition is more than $40 \mathrm{wt}$.\%. The maximum evaporation velocity of lead is about $2.02 \times 10^{-3} \mathrm{~g} / \mathrm{cm}^{2} \mathrm{~s}$, which is close to the evaporation velocity of pure metallic lead at $1073 \mathrm{~K}$ and $0.1 \mathrm{~Pa}$ [31]. However, the percentage of lead in the original mixture of $40 \mathrm{wt} . \%$ funnel glass addition is only $10.63 \mathrm{wt} . \%$, indicating SHS evaporation process is efficient and the lead extraction velocity is high enough to meet the production requirement. Furthermore, the self-exothermic character of the SHS process avoids the need for expensive processing facilities and equipment. It is also suitable for the in situ disposal of small amount of hazardous wastes, which may not be easily transported from one place to another.

\subsection{Characteristics of extracted nanoparticles}

The extracted powders after SHS treatment were collected from the internal wall of the reactor. X-ray diffraction patterns of the extracted powders are presented in Fig. 6 for the SHS reaction with

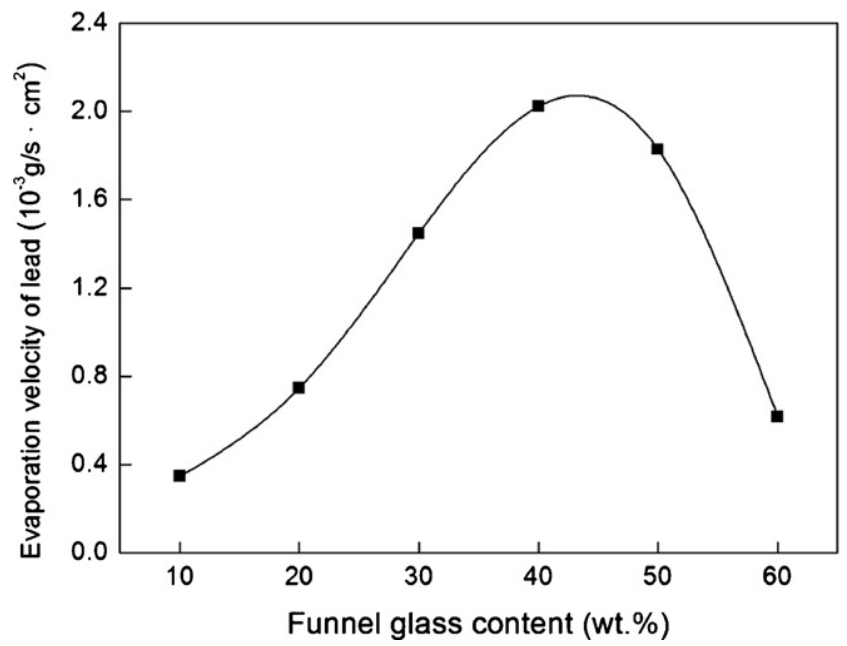

Fig. 5. The dependence of the evaporation velocity of lead on the funnel glass addition. 


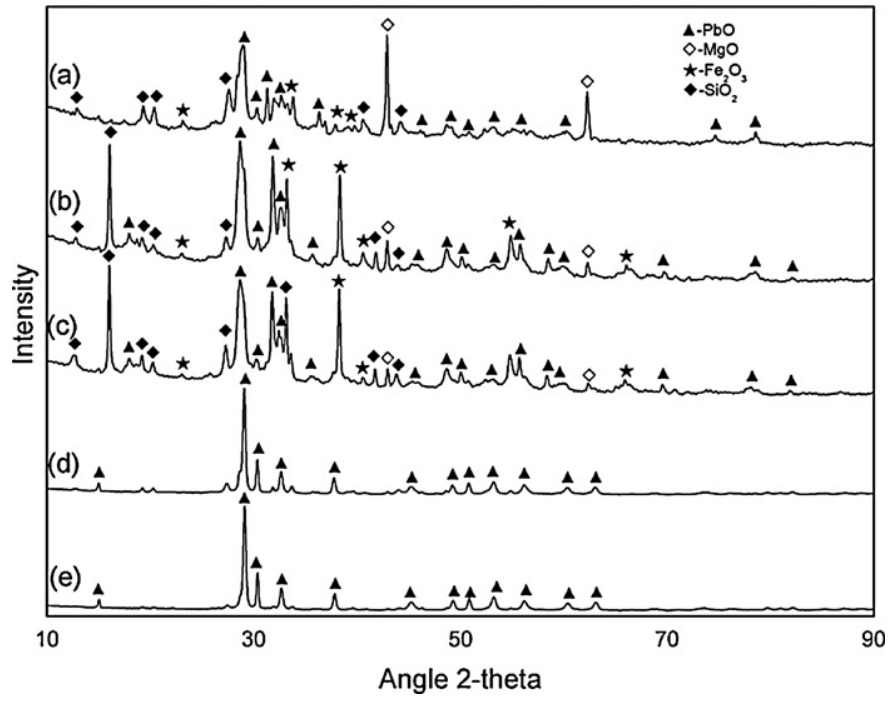

Fig. 6. XRD patterns of extracts with various funnel glass amount added in the original mixture: (a) $10 \mathrm{wt} . \%$, (b) $20 \mathrm{wt} . \%$, (c) $30 \mathrm{wt} . \%$, (d) $40 \mathrm{wt} . \%$, and (e) $50 \mathrm{wt} . \%$.

10-50 wt.\% funnel glass addition. It was found that the crystalline compositions of the powders depend on the ratio of funnel glass employed. When the funnel glass addition is equal to or more than $40 \mathrm{wt} . \%$, the single PbO (PDF card \#65-1471) phase was extracted from the original funnel glass, implying a relatively high purity. Fig. 7 shows the chemical components of the extracted powders with different funnel glass addition from $10 \mathrm{wt} . \%$ to $40 \mathrm{wt} . \%$ among which the lead extraction ratios were all above 90 wt.\% (cf. Fig. 3). It could be found that a small portion of other elements (i.e., Fe, $\mathrm{Mg}, \mathrm{Na}, \mathrm{K}$ and others which contain $\mathrm{Si}, \mathrm{Ca}, \mathrm{Al}$ ) also evaporated from the CRT funnel glass. The PbO powders obtained with relatively high lead content, and the lead concentration increases with the increased funnel glass addition. When the funnel glass content reaches $40 \mathrm{wt} . \%$, the lead concentration is about $70 \mathrm{wt} . \%$.

Fig. 8 shows the typical SEM micrographs of the powders under conditions of $30 \mathrm{wt} . \%, 40 \mathrm{wt} . \%$ and $50 \mathrm{wt} . \%$ funnel glass addition. It is apparent to point out that the collected particles were compacted and necked with each other because of electrostatic effect and agglomerates were formed within very small average size. Furthermore, a more spherical shape of agglomerates was obtained when the combustion temperature is no more than $2008 \mathrm{~K}$ (cf.

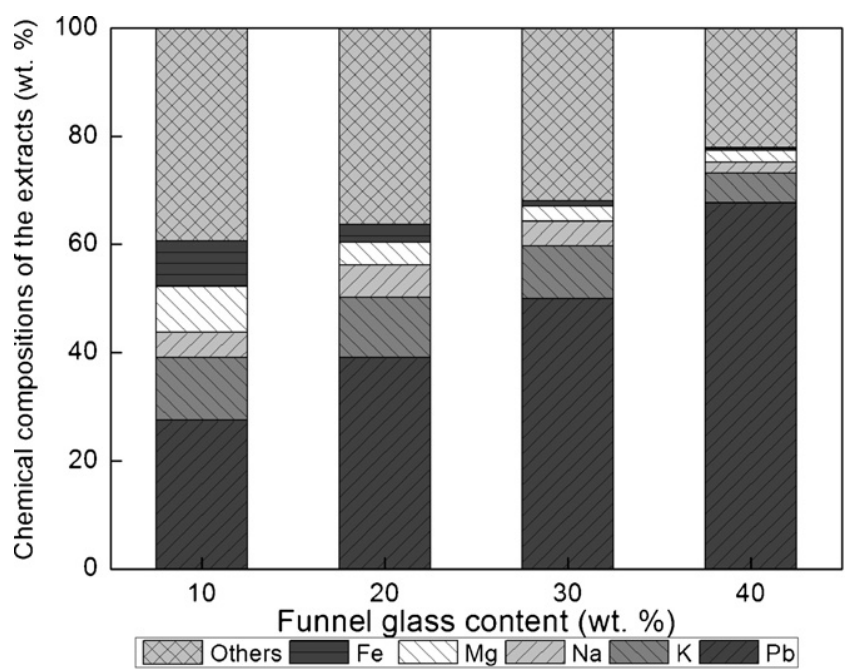

Fig. 7. Chemical compositions of the extracted lead oxide powders with various funnel glass addition.
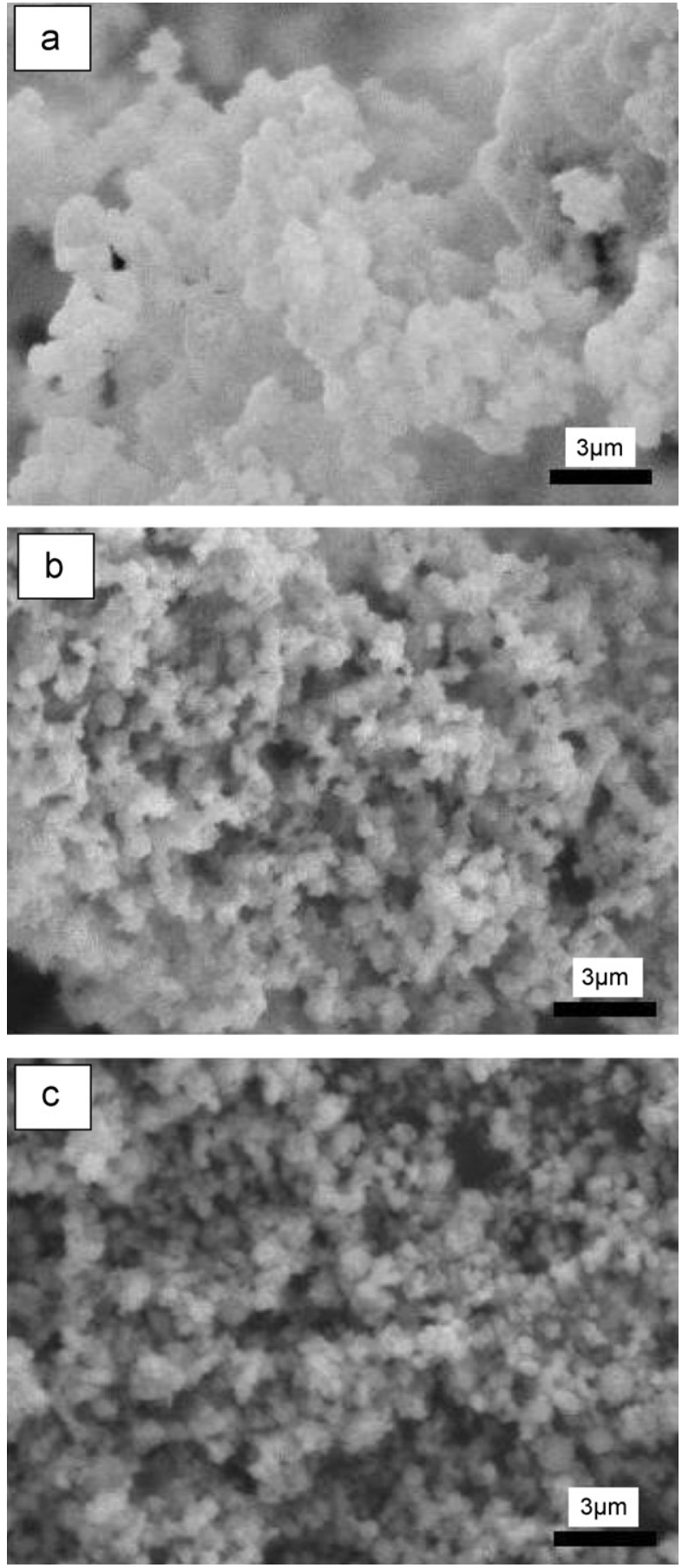

Fig. 8. Representative SEM micrographs of the extracted powders: (a) funnel glass $=30 \mathrm{wt} . \%, T_{\mathrm{c}}=2237 \mathrm{~K}$, (b) funnel glass $=40 \mathrm{wt} . \%, T_{\mathrm{c}}=2008 \mathrm{~K}$, (c) funnel glass $=50 \mathrm{wt} . \%, T_{\mathrm{C}}=1832 \mathrm{~K}$.

Fig. 6b, c). This might be attributed to the rapid solidification of the vapor phase at low combustion temperature in the result of the change of surface tension during condensation process [32-34].

Fig. 9 shows the typical TEM images of extracted powders under different combustion temperature with 10-50 wt.\% funnel glass addition. It is important to note that a number of relatively large agglomerates were also observed in each TEM picture, which indicated that the obtained powders, condensed with rapid cooling rate, was not easy to be dispersed by ultrasonic dispersion operation in the presence of ethanol. However, samples with $40 \%$ and $50 \%$ funnel glass addition (cf. Fig. 9d, e) show a better dispersion and 

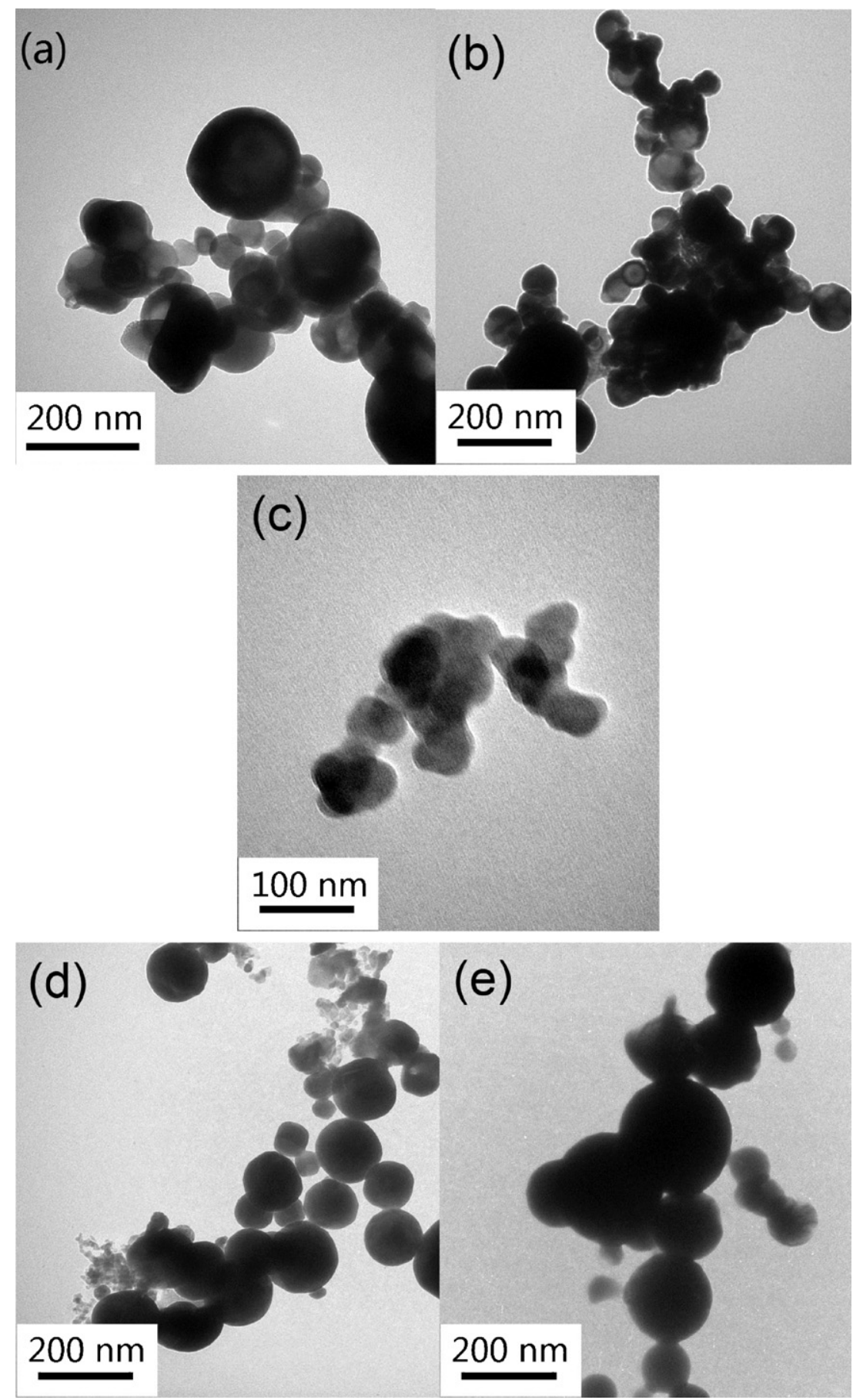

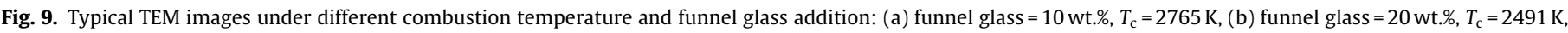
(c) funnel glass $=30 \mathrm{wt} . \%, T_{\mathrm{c}}=2237 \mathrm{~K}$, (d) funnel glass $=40 \mathrm{wt} . \%, T_{\mathrm{c}}=2008 \mathrm{~K}$, (e) funnel glass $=50 \mathrm{wt} . \%, T_{\mathrm{c}}=1832 \mathrm{~K}$.

morphology. And the particles are almost spherical in shape with a grain size of a few dozen nanometers. The mean grain size ranged from 20 to $40 \mathrm{~nm}$ in the cases of 10-30 wt.\% funnel glass addition, while the mean grain size was within $40-50 \mathrm{~nm}$ when the amount of funnel glass is $40 \mathrm{wt} . \%$ and $50 \mathrm{wt} . \%$.

In addition, the grain sizes of extracted nanoparticles could be also determined by Scherrer's formula in Eq. (3):

$D=\frac{K \lambda}{\beta \cos \theta}$

where $D$ is the particles size, $\lambda$ is the $\mathrm{X}$-ray wavelength, $\beta$ is the full width at half-maximum intensity of the XRD peak, $\theta$ is the diffraction angle and $K$ is the Scherrer constant, which mainly depends on the how the width is determined, the shape of the crystal, and the size distribution. The most common values for $K$ are 0.89 for spherical crystals and 0.94 for cubic crystals. As observed in the TEM images, the obtained nanoparticles were spherical, thus 0.89 was chosen as the Scherrer constant $[35,36]$.

It could be found from the X-ray diffraction patterns of the extracted nanoparticles (cf. Fig. 6) that the samples (d) and (e) show a good crystalline state and the intensity is high. They are the lead oxide extracted from the SHS reactions with $40 \mathrm{wt} . \%$ and $50 \mathrm{wt} . \%$ addition of funnel glass. The full width at half-maximum intensity of the XRD peak with the highest strength $\left(2 \theta=29^{\circ}\right)$ was 
Table 5

TCLP results and $\mathrm{Pb}$ content remained in the residue.

\begin{tabular}{lcl}
\hline Funnel glass addition (wt.\%) & $\begin{array}{l}\text { Pb in the residue } \\
(\mathrm{g} / \mathrm{kg})\end{array}$ & TCLP of Pb (mg/L) \\
\hline 10.00 & 1.288 & $0.098 \pm 0.032$ \\
20.00 & 2.424 & $0.089 \pm 0.039$ \\
30.00 & 3.280 & $0.175 \pm 0.084$ \\
40.00 & 6.363 & $0.017 \pm 0.001$ \\
50.00 & 23.488 & $0.067 \pm 0.020$ \\
60.00 & 113.560 & $0.095 \pm 0.031$ \\
& & $5.0^{\mathrm{a}}$ \\
\hline
\end{tabular}

a Maximum allowable concentrations according to the EPA regulations.

adopted to calculate grain sizes of the nanoparticles. And the calculated sizes are 33.1 and $32.9 \mathrm{~nm}$ for the samples (d) and (e), respectively. Those values estimated from Scherrer's formula were only a little smaller than the size $(40-50 \mathrm{~nm})$ observed by TEM. However, as for the samples (a), (b) and (c), their X-ray diffraction patterns indicated a not good crystalline state. The uneven baseline of background of the crystalline fraction from X-ray diffraction demonstrates the formation of amorphous phase in the samples. Besides, those particles were collected from the SHS reactions at more than $2237 \mathrm{~K}$ with the funnel glass addition of less than $30 \%$. It can be concluded that the XRD peak broadening might be due to the inhomogeneous strain existed in the quenched samples which was caused by relatively high combustion temperature reached during self-propagating process and rapid cooling rate after reaction [37]. Thus, it is difficult to estimate the crystallite sizes of samples (a), (b) and (c) through the Scherrer method.

\subsection{Toxicity of residues}

Although most of lead was separated from funnel glass when the added funnel glass amount was no more than $40 \mathrm{wt} . \%$ after SHS process, the residues containing a little amount of lead might still leach out of toxic heavy metals. Thus, toxic leachability was measured using the TCLP method and the results were presented in Table 5. It's worth noting that all the determined leaching concentrations were well within the current regulatory despite the various funnel glass ratios, which indicates that CRT funnel glass was effectively detoxified after self-propagating process. In addition, as is shown in Fig. 2, the main crystalline phases of the residues are $\mathrm{Mg}_{2} \mathrm{SiO}_{4}, \mathrm{MgO}$ and Fe. To our best knowledge, both $\mathrm{Mg}_{2} \mathrm{SiO}_{4}$ and $\mathrm{MgO}$ have numerous applications in several industries, especially in the refractory industry due to their physical and chemical stability at high temperature [38]. However, further study is needed to know the characteristics of developed material before it can be applied in the refractory industry.

\subsection{Conclusion and recommendation}

Based on the experimental results above, it could be concluded that SHS method is an effective method to prepare lead oxide nanoparticles from cathode-ray tube funnel glass. Also, the waste CRT could be detoxified through the self-propagating reaction of $\mathrm{Mg}$ and $\mathrm{Fe}_{2} \mathrm{O}_{3}$. The CRT is mainly a dilute agent in the SHS process, both the combustion temperature and lead extraction ratio decrease with the increased funnel glass addition. When the funnel glass addition equal to $40 \mathrm{wt}$.\% in the original mixture, over $90 \mathrm{wt} . \%$ of lead could be extracted from funnel glass and the PbO nanoparticles collected show good dispersion and morphology with a mean grain size of $40-50 \mathrm{~nm}$. Meanwhile, TCLP test indicated that lead leaching concentration from the residual is only $0.02-0.18 \mathrm{mg} / \mathrm{L}$. In some degree, it would guarantee the safety of heavy metal during future reuse process.

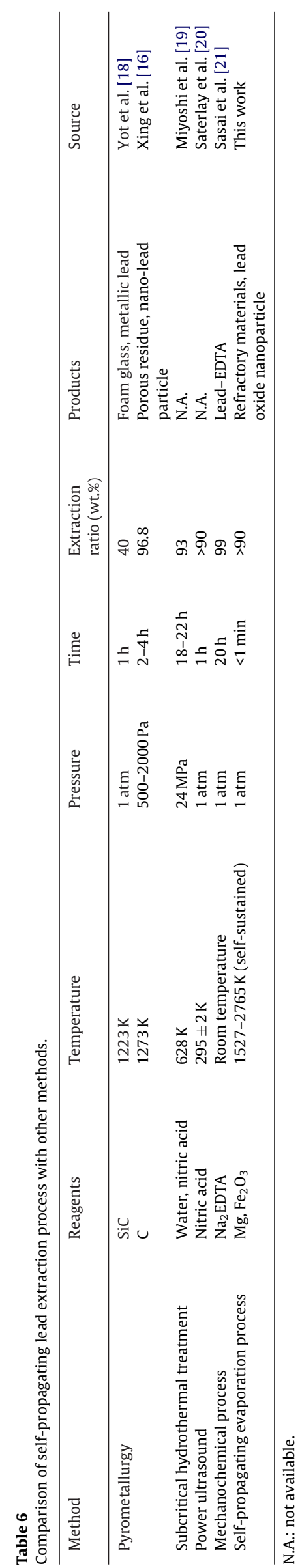


The comparison result of lead extraction from CRTs between SHS and other methods was presented in Table 6. Extraction methods discussed here mainly include pyrometallurgy, subcritical hydrothermal treatment, power ultrasound, mechano- chemical process and SHS process (this work). The reaction parameters concerned for each method was listed in the table. The results suggests that the self-propagating process is effective and efficient technology to reduce the time and energy consumption, which can be an alternative of conventional thermal treatment of waste CRTs and the simplicity is also a major merit of SHS process. However, it should be noted that $\mathrm{Mg}$ is relatively expensive as a self-propagating reducing reagent for the waste treatment, limiting its industrialization in hazardous treatment. Thus, seeking of more suitable self-propagating reactants with relatively low cost is an important development direction in the near future.

\section{Acknowledgement}

This work was financially supported, in part, by the National Natural Science Foundation of China (20977105 and 50708110).

\section{References}

[1] M. Allsopp, D. Santillo, P. Johnston, Environmental and human health concerns in the processing of electrical and electronic Waste, Greenpeace Research Laboratories, 2006, Available from: http://www.greenpeace.to/ publications/Ewastetreatment-May2006-FINAL.pdf.

[2] Y.C. Jang, T.G. Townsend, Leaching of lead from computer printed wire boards and cathode ray tubes by municipal solid waste landfill leachates, Environ. Sci. Technol. 37 (2003) 4778-4784.

[3] F. Mear, P. Yot, M. Cambon, M. Ribes, The characterization of waste cathode-ray tube glass, Waste Manage. 26 (2006) 1468-1476.

[4] J.R. Gregory, M.C. Nadeau, R.E. Kirchain, Evaluating the economic viability of a material recovery system: the case of cathode ray tube glass, Environ. Sci. Technol. 43 (2009) 9245-9251.

[5] X.B. Liu, M. Tanaka, Y. Matsui, Electrical and electronic waste management in China: progress and the barriers to overcome, Waste Manage. Res. 24 (2006) 92-101.

[6] X.W. Chi, M. Streicher-Porte, M.Y.L. Wang, M.A. Reuter, Informal electronic waste recycling: a sector review with special focus on China, Waste Manage. 31 (2011) 731-742.

[7] Y.C. Wang, Y.H. Ru, A. Veenstra, R.J. Wang, Y. Wang, Recent developments in waste electrical and electronics equipment legislation in China, Int. J. Adv. Manuf. Technol. 47 (2010) 437-448.

[8] C.H. Lee, C.S. Hsi, Recycling of scrap cathode ray tubes, Environ. Sci. Technol. 36 (2002) 69-75.

[9] G. Tchobanoglous, F. Kreith, Handbook of Solid Waste Management, 2nd ed., McGraw-Hill, 2002.

[10] S.E. Musson, Y.C. Jang, T.G. Townsend, I.H. Chung, Characterization of lead leachability from cathode ray tubes using the toxicity characteristic leaching procedure, Environ. Sci. Technol. 34 (2000) 4376-4381.

[11] R. Kahhat, E. Williams, Product or waste? Importation and end-of-life processing of computers in Peru, Environ. Sci. Technol. 43 (2009) 6010-6016.

[12] A. Witkowska, J. Rybicki, K. Trzebiatowski, A. Di Cicco, M. Minicucci, Influence of hydrogen reduction on the structure of $\mathrm{PbSiO}_{3}$ glass: an EXAFS study, J. NonCryst. Solids 276 (2000) 19-26.

[13] A. Witkowska, J. Rybicki, A. Di Cicco, Structure of partially reduced $x \mathrm{PbO}$ $(1-x) \mathrm{SiO}_{2}$ glasses: combined EXAFS and MD study, J. Non-Cryst. Solids 351 (2005) 380-393.
[14] F.O. Mear, P.G. Yot, A.V. Kolobov, M. Ribes, M.F. Guimon, D. Gonbeau, Local structure around lead, barium and strontium in waste cathode-ray tube glasses, J. Non-Cryst. Solids 353 (2007) 4640-4646.

[15] P.G. Yot, F.O. Mear, Influence of AlN, TiN and SiC reduction on the structural environment of lead in waste cathode-ray tubes glass: an x-ray absorption spectroscopy study, J. Phys-Condens. Mater. 21 (2009), doi:10.1088/0953$8984 / 21 / 28 / 285104$.

[16] M. Xing, F.S. Zhang, Nano-lead particle synthesis from waste cathode ray-tube funnel glass, J. Hazard. Mater. (2011), doi:10.1016/j.jhazmat.2011.08.003.

[17] M.J. Chen, F.S. Zhang, J.X. Zhu, Lead recovery and the feasibility of foam glass production from funnel glass of dismantled cathode ray tube through pyrovacuum process, J. Hazard. Mater. 161 (2009) 1109-1113.

[18] P.G. Yot, F.O. Mear, Lead extraction from waste funnel cathode-ray tubes glasses by reaction with silicon carbide and titanium nitride, J. Hazard. Mater. 172 (2009) 117-123.

[19] H. Miyoshi, D.P. Chen, T. Akai, A novel process utilizing subcritical water to remove lead from wasted lead silicate glass, Chem. Lett. 33 (2004) 956-957.

[20] A.J. Saterlay, S.J. Wilkins, R.G. Compton, Towards greener disposal of waste cathode ray tubes via ultrasonically enhanced lead leaching, Green Chem. 3 (2001) 149-155.

[21] R. Sasai, H. Kubo, M. Kamiya, H. Itoh, Development of an eco-friendly material recycling process for spent lead glass using a mechanochemical process and $\mathrm{Na}_{2}$ EDTA reagent, Environ. Sci. Technol. 42 (2008) 4159-4164.

[22] J.J. Moore, H.J. Feng, Combustion synthesis of advanced materials. 1. Reaction parameters, Prog. Mater. Sci. 39 (1995) 243-273.

[23] J.B. Wiley, R.B. Kaner, Rapid solid-state precursor synthesis of materials, Science 255 (1992) 1093-1097.

[24] R. Orru, M. Sannia, A. Cincotti, G. Cao, Treatment and recycling of zinc hydrometallurgical wastes by self-propagating reactions, Chem. Eng. Sci. 54 (1999) 3053-3061.

[25] M. Sannia, R. Orru, A. Concas, G. Cao, Self-propagating reactions for environmental protection: remarks on the treatment and recycling of zinc hydrometallurgical wastes, Ind. Eng. Chem. Res. 40 (2001) 801-807.

[26] K.S. Wang, K.L. Lin, C.H. Lee, Melting of municipal solid waste incinerator fly ash by waste-derived thermite reaction, J. Hazard. Mater. 162 (2009) 338-343.

[27] J.G. Speight, Lange's Handbook of Chemistry, 16th ed., McGraw-Hill, 2004.

[28] U.S. EPA, Test Methods for Evaluating Solid Waste, Office of Solid Waste, Washington, DC, 1996.

[29] L. Zhan, Z.M. Xu, Application of vacuum metallurgy to separate pure metal from mixed metallic particles of crushed waste printed circuit board scraps, Environ. Sci. Technol. 42 (2008) 7676-7681.

[30] D.W. Green, R.H. Perry, Perry's Chemical Engineers' Handbook, 8th ed., McGraw-Hill, 2008.

[31] B. Yang, Y.N. Dai, Evaporation of lead in vacuum, J. Kunming Univ. Sci. Technol. 23 (1998) 116-120 (in Chinese).

[32] M. Turker, Effect of production parameters on the structure and morphology of Ag nanopowders produced by inert gas condensation, Mater. Sci. Eng. A-Struct. Mater. Prop. Microstruct. Process. 367 (2004) 74-81.

[33] A. Simchi, R. Ahmadi, S.M.S. Reihani, A. Mahdavi, Kinetics and mechanisms of nanoparticle formation and growth in vapor phase condensation process, Mater. Des. 28 (2007) 850-856.

[34] S.H. Ehrman, M.I. Aquino-Class, M.R. Zachariah, Effect of temperature and vapor-phase encapsulation on particle growth and morphology, J. Mater. Res. 14 (1999) 1664-1671.

[35] D. Zhou, H. Wang, X. Yao, L.-X. Pang, H.-F. Zhou, Nanopowder Preparation and dielectric properties of a $\mathrm{Bi}_{2} \mathrm{O}_{3}-\mathrm{Nb}_{2} \mathrm{O}_{5}$ binary system prepared by the highenergy Ball-Milling method, J Am. Ceram. Soc. 91 (2008) 139-143.

[36] J.I. Langford, A.J.C. Wilson, Scherrer after sixty years: a survey and some new results in the determination of crystallite size, J. Appl. Cryst. 11 (1978) $102-113$.

[37] S.H. Hosseini, S. Sheibani, Z. Valefi, Characterisation of aluminium nanopowder produced by evaporation-condensation method, Mater. Sci. Technol. 26(2010) 1207-1212.

[38] P. Patnaik, Handbook of Inorganic Chemicals, McGraw-Hill, 2003. 